Article

\title{
Synthesis of $\beta$-cyclodextrin-Based Star Block Copolymers with Thermo-Responsive Behavior
}

\author{
Agnes Wycisk ${ }^{1}$, Artjom Döring ${ }^{1}$, Martin Schneider ${ }^{1}$, Monika Schönhoff ${ }^{2}$ and Dirk Kuckling ${ }^{1, *}$ \\ 1 Organic and Macromolecular Chemistry, Chemistry Department, University of Paderborn, \\ 33098 Paderborn, Germany; E-Mails: agnes.wycisk@uni-paderborn.de (A.W.); \\ artjom.doering@uni-paderborn.de (A.D.); schneid2@mail.uni-paderborn.de (M.S.) \\ 2 Institute of Physical Chemistry, University of Münster, Corrensstr. 30, D-48149 Münster, Germany; \\ E-Mail: schonhoff@uni-muenster.de
}

* Author to whom correspondence should be addressed; E-Mail: dirk.kuckling@uni-paderborn.de; Tel.: +49-5251-602171; Fax: +49-5251-603245.

Academic Editor: Alexander Böker

Received: 18 March 2015 / Accepted: 27 April 2015 / Published: 6 May 2015

\begin{abstract}
Star polymers are one example of three-dimensional macromolecules containing several arms with similar molecular weight connected to a central core. Due to their compact structure and their enhanced segment density in comparison to linear polymers of the same molecular weight, they have attracted significant attention during recent years. The preparation of block-arm star copolymers with a permanently hydrophilic block and an "environmentally" sensitive block, which can change its nature from hydrophilic to hydrophobic, leads to nanometer-sized responsive materials with unique properties. These polymers are able to undergo a conformational change or phase transition as a reply to an external stimulus resulting in the formation of core-shell nanoparticles, which further tend to aggregate. Star-shaped copolymers with different cores were synthesized via atom transfer radical polymerization (ATRP). The core-first method chosen as synthetic strategy allows good control over the polymer architecture. First of all the multifunctional initiators were prepared by esterification reaction of the hydroxyl groups with 2-chloropropionyl chloride. Using $\beta$-cyclodextrin as core molecules, which possess a well-defined number of functional groups up to 21, allows defining the number of arms per star polymer. In order to prepare stimuli-responsive multi-arm copolymers, containing a stimuli-responsive (poly( $N$-isopropylacrylamide) (PNIPAAm)) and a non-responsive block (poly $(N, N$-dimethylacrylamide) (PDMAAm)), consecutive ATRP was carried out. The polymers were characterized intensively using NMR spectroscopy
\end{abstract}


and size exclusion chromatography (SEC), whereas the temperature-depending aggregation behavior in aqueous solution was determined via turbidimetry and differential scanning calorimetry (DSC).

Keywords: ATRP; star block copolymers; $\beta$-cyclodextrin; NIPAAm; DMAAm

\section{Introduction}

Star polymers are an example of three-dimensional macromolecules consisting of several linear polymer chains connected at a central core. Throughout the last few decades, such polymers have provoked more and more interest due to their compact structure and their enhanced segment density in comparison to their linear counterparts [1].

The synthesis of star polymers was first realized using ionic polymerization techniques [2]. However, this method has its limitations in terms of the small range of applicable monomers. With the development of controlled radical polymerization (CRP) in the mid-1990s, a new and powerful tool was found to create polymers with complex architectures. Beside nitroxide-mediated radical polymerization (NMRP) [3,4] and reversible addition fragmentation chain transfer polymerization (RAFT) [5,6], atom transfer radical polymerization (ATRP) can be highlighted in particular [7,8]. The synthetic procedures providing well-defined star macromolecules can be divided into three different categories: the "arm-first" approach $[9,10]$ involves the cross-linking of linear arm precursors with a cross-linking agent; the "coupling-onto" approach [11,12] comprises the grafting of linear arm precursors onto a well-defined multifunctional core; and the "core-first" approach $[13,14]$ requires the use of a multifunctional initiator (core) to initiate the growth of the polymer chains. A variety of low-molecular weight compounds used as core molecules are described in literature [15-17]. The chemical structure of these initiators can either be aliphatic or cyclic and generally involves more than three groups for initiation. The cyclic oligosaccharide $\beta$-cyclodextrin consisting of seven $\alpha-(1-4)$ linked D-glucopyranose units and a defined number of primary (7) and secondary (14) hydroxyl groups represents a candidate with a cyclical structure. Their selective modification leads to efficient multifunctional initiators for the synthesis of star polymers [18-21].

In 2001 Haddleton and coworkers [18] first reported the complete functionalization of $\beta$-cyclodextrin with 2-bromoisobutyric anhydride and the synthesis of poly(methyl methacrylate) (PMMA) and poly(styrene) (PS) star polymers. Adeli et al. [20] used a tosylated cyclodextrin ((Tosyl)7- $\beta$-CD), which contained two types of functional groups to synthesize amphiphilic star copolymers with poly(lactide) and poly(2-ethyl-2-oxazoline) arms connected to a $\beta$-cyclodextrin core via ring opening polymerization. Zhu and coworkers [22] described the synthesis of amphiphilic $\mathrm{A}_{14} \mathrm{~B}_{7}$ multi-miktoarm star copolymers composed of 14 poly( $\varepsilon$-caprolactone) (PCL) arms and 7 poly(acrylic acid) (PAA) arms with $\beta$-cyclodextrin $(\beta-C D)$ as core moiety employing controlled ring-opening polymerization (CROP) and ATRP. Most of the so far mentioned $\beta$-cyclodextrin based star polymers are insoluble in water. In order to create water-soluble star polymers with $\beta$-cyclodextrin cores, polymers of $N$-isopropylacrylamide (NIPAAm) are highly interesting. PNIPAAm-based polymers are water soluble up to $32{ }^{\circ} \mathrm{C}$. Higher temperatures induce a phase transition (LCST, lower critical solution temperature), which results in an aggregation of 
the polymer chains [23]. Liu et al. [24] used a combination of ATRP and click coupling chemistry to generate one of the first $\beta$-cyclodextrin based PNIPAAm star polymers with up to 21 arms. These star polymers were not only water-soluble, but also stimuli-sensitive, since these polymers respond to external incitation. Rubira and coworkers [25] reported the synthesis of PNIPAAm star polymers using a $\beta$-cyclodextrin core macroinitiator by means of ATRP in water. However, the polydispersity of these polymers ranged from 1.60 to 4.04 due to collapse of the PNIPAAm chains at temperatures above the LCST.

We are interested in the application of (star-shaped) temperature-responsive polymer systems, which can be tailored to form nanometer-sized micelles. Applying different monomers, polymerization techniques (ATRP, RAFT) and post-modification of the resulting polymers by polymer analogue reactions or click chemistry, these micelles can be tuned, e.g., for the application in catalytic reactions. When temperature-responsive polymers (exhibiting a LCST or UCST (upper critical solution temperature) behavior) are used for catalyst preparation, the micellar catalyst system can be directly separated from the surrounding medium after heating or cooling to the critical temperature. In this work, we present the synthesis of $\beta$-cyclodextrin based marcoinitiators bearing 7, 14 and even 21 initiation sites, which is one potential system for the design of micellar structures. The selective functionalization was realized by specific protection-deprotection methods. These macroinitiators were used for the synthesis of PNIPAAm homo star polymers via copper(I)-mediated ATRP employing the "core-first" approach. In a second step, block copolymers consisting of a temperature-responsive inner block (PNIPAAm) and a non-responsive outer block (PDMAAm) were generated using consecutive ATRP. We also analyzed the degree of branching for the PNIPAAm homo polymers by triple SEC and the temperature-dependent aggregation of the homo and block copolymer by dynamic light scattering. These results will be published separately.

\section{Experimental Section}

\subsection{Materials}

Acetonitrile (Fisher Scientific, Schwerte, Germany, $>99 \%$ ) was dried over $3 \AA$ molecular sieves, $\beta$-cyclodextrin hydrate (Fluka, Buchs, Switzerland,) was dried in vacuo at $105{ }^{\circ} \mathrm{C}$ overnight and was stored under argon. Copper(I)chloride ( $\mathrm{CuCl}$, Aldrich, St. Louis, MO, USA, $\geq 99.999 \%$ ) was purified by stirring in glacial acetic acid overnight, rinsing with cold ethanol and diethyl ether and dried in vacuo. Copper(II)chloride $\left(\mathrm{CuCl}_{2}\right)$ was obtained from copper(II)chloride dihydrate (Aldrich, $\geq 99.999 \%$ ) by heating at $100{ }^{\circ} \mathrm{C}$ overnight in vacuo. $\mathrm{N}, \mathrm{N}$-dimethylacrylamide (DMAAm, TCI Europe, Eschborn, Germany, >99\%) was distilled in vacuo before use and was stored at $-20{ }^{\circ} \mathrm{C}$ under argon. 4-(Dimethylamino)pyridine (DMAP, Acros Organics, Geel, Belgium, 99\%) was purified by recrystallization from toluene. $N$-Isopropylacrylamide (NIPAAm, TCI Europe, $\geq 98 \%$ ) was purified by recrystallization from $n$-hexane and stored at $-10{ }^{\circ} \mathrm{C}$. Pyridine (Fluka, $\geq 99.8 \%$ ) and triethylamine (TEA, Grüssing, Filsum, Germany, $\geq 99 \%$ ) were distilled over potassium hydroxide and stored under argon. Tris[2-(dimethylamino)ethyl]amine (Me6TREN) was prepared according to the literature [26]. Tert-butyldimethylsilyl chloride (Aldrich, 97\%), 2-chloropropionyl chloride (CPC, Aldrich, 97\%), $\mathrm{N}, \mathrm{N}$-dimethylacetamide (DMAc, Acros Organics, 99,5\%, extra dry), dimethyl sulfoxide (DMSO, Acros, 
$\geq 99.7 \%$, extra dry, over molecular sieves), methyl iodide (MERCK-Schuhardt, Darmstadt, Germany, $\geq 99 \%$ ), sodium hydride (Aldrich, 95\%) and tetrabutylammonium fluoride solution (TBAF, Acros Organics, $1 \mathrm{M}$ in THF) were used as received.

\subsection{Synthesis of Multifunctional ATRP Initiators}

Heptakis-(6-(tert-butyldimethylsilyl)oxy)- $\beta$-cyclodextrin (1) was prepared from $\beta$-cyclodextrin as described in literature [27]. (1) was permethylated by an excess of MeI to yield hepatkis-(6-(tertbutyldimethylsilyl)oxy-2,3-di-O-methyl)- $\beta$-cyclodextrin (2) [28]. The desilylation of (2) was accomplished with tetra- $n$-butylammonium fluoride solution ( $1 \mathrm{M}$ in THF) in order to obtain heptakis-(2,3-di-O-methyl)- $\beta$-cyclodextrin (3) [29].

\subsection{Synthesis of Heptakis-(6-O-chloropropionyl-2,3-di-O-methyl)- $\beta$-cyclodextrin (4) (7-Cl- $\beta$-CD)}

Vacuum dried heptakis-(2,3-di-O-methyl)- $\beta$-cyclodextrin (3) $(0.4 \mathrm{~g}(0.3 \mathrm{mmol}))$ and DMAP (10 mg $(0.08 \mathrm{mmol}))$ were dissolved in anhydrous DMAc $(8 \mathrm{~mL})$ and cooled to $0{ }^{\circ} \mathrm{C}$. 2-Chloropropionyl chloride $(0.41 \mathrm{~mL}(4.2 \mathrm{mmol}))$ was added to the solution under argon using a syringe within $1 \mathrm{~h}$. The reaction was carried out at $0{ }^{\circ} \mathrm{C}$ for $1 \mathrm{~h}$ and then at $50{ }^{\circ} \mathrm{C}$ for 3 days. Afterwards water $(20 \mathrm{~mL})$ was added to the reaction mixture and the aqueous solution was extracted with chloroform $(3 \times 100 \mathrm{~mL})$. The combined organic layers were dried over anhydrous magnesium sulfate and the solvent was removed under reduced pressure. The crude product was purified by column chromatography on silica gel (chloroform/methanol: 97:3, $R_{\mathrm{f}}=0.25$ ). The pure product was obtained as a colorless solid (yield: $28 \%$ ): $m_{\mathrm{p}}=104-105{ }^{\circ} \mathrm{C} ;{ }^{1} \mathrm{H}$ NMR $\left(500 \mathrm{MHz}, \mathrm{CDCl}_{3}\right): \delta(\mathrm{ppm})=5.08-5.04(\mathrm{~m}, 1 \mathrm{H}, H-1), 4.63-4.25(m, 3 \mathrm{H}$, $\left.H-6,-\mathrm{CH}\left(\mathrm{CH}_{3}\right) \mathrm{Cl}\right), 3.92(m, 1 \mathrm{H}, H-5), 3.64-3.45\left(m, 8 \mathrm{H},-\mathrm{OCH}_{3}, H-3, H-4\right), 3.16(m, 1 \mathrm{H}, H-2)$, 1.70-1.67 $\left(m, 3 \mathrm{H},-\mathrm{CH}\left(\mathrm{CH}_{3}\right) \mathrm{Cl}\right) .{ }^{13} \mathrm{C} \mathrm{NMR}\left(125 \mathrm{MHz}, \mathrm{CDCl}_{3}\right): \delta(\mathrm{ppm})=169.6-169.3(\mathrm{C}=\mathrm{O})$, 99.5-99.1 (C-1), 82.0-81.7 (C-4), 81.5-81.4 (C-2), 81.1-80.3 (C-3), 69.9-69.7 (C-5), 64.8-64.6 (C-6), 61.6-61.4 $\left(-\mathrm{OCH}_{3}\right), \quad 58.9-58.6 \quad\left(-\mathrm{OCH}_{3}\right), \quad 52.7-52.4 \quad\left(-\mathrm{CH}\left(\mathrm{CH}_{3}\right) \mathrm{Cl}\right), \quad 21.5-21.3 \quad\left(-\mathrm{CH}\left(\mathrm{CH}_{3}\right) \mathrm{Cl}\right)$. IR $(\mathrm{KBr}): \widetilde{v}\left(\mathrm{~cm}^{-1}\right)=3460,2935,2837\left(v_{\mathrm{C}-\mathrm{H}}\right), 1750\left(v_{\mathrm{C}=\mathrm{O}}\right), 1451,1381\left(v_{\mathrm{C}-\mathrm{H}}\right), 753,682\left(v_{\mathrm{C}-\mathrm{Cl}}\right)$.

\subsection{Synthesis of Heptakis-(6-(tert-butyldimethysilyl)oxy-2,3-di-O-chloropropionyl)- $\beta$-cyclodextrin (5) $(14-C l-\beta-C D)$}

Heptakis-(6-(tert-butyldimethylsilyl)oxy)- $\beta$-cyclodextrin (1) $(0.45 \mathrm{~g}(0.23 \mathrm{mmol}))$, imidazole $(0.45 \mathrm{~g}$ $(6.6 \mathrm{mmol}))$ and DMAP $(10 \mathrm{mg}(0.08 \mathrm{mmol}))$ were dissolved in anhydrous DMAc $(8 \mathrm{~mL})$ and cooled to $0{ }^{\circ} \mathrm{C}$. 2-Chloropropionyl chloride $(0.64 \mathrm{~mL}(6.6 \mathrm{mmol}))$ was added to the solution under argon using a syringe within $1 \mathrm{~h}$. The reaction was carried out at $0{ }^{\circ} \mathrm{C}$ for $1 \mathrm{~h}$ and then at $50{ }^{\circ} \mathrm{C}$ for 3 days. Afterwards the mixture was added drop wise into water. The precipitate was collected, dissolved in THF, precipitated in water again and finally dried in vacuo at $80{ }^{\circ} \mathrm{C}$. The product was obtained as a colorless solid (yield: 48\%): $m_{\mathrm{p}}=187-191{ }^{\circ} \mathrm{C} .{ }^{1} \mathrm{H}$ NMR $\left(500 \mathrm{MHz}, \mathrm{CDCl}_{3}\right): \delta(\mathrm{ppm})=5.58-3.74(\mathrm{~m}$, sugar residues and $\left.-\mathrm{CH}\left(\mathrm{CH}_{3}\right) \mathrm{Cl}\right), 1.71\left(m,-\mathrm{CH}\left(\mathrm{CH}_{3}\right) \mathrm{Cl}\right), 0.88\left(s,-\mathrm{SiC}\left(\mathrm{CH}_{3}\right)_{3}\right), 0.04\left(s,-\mathrm{Si}\left(\mathrm{CH}_{3}\right)_{2}\right) .{ }^{13} \mathrm{C}$ NMR $\left(125 \mathrm{MHz}, \mathrm{CDCl}_{3}\right): \delta(\mathrm{ppm})=169.3(\mathrm{C}=\mathrm{O}), 98.3,74.2,72.1,70.6,64.0,61.6$ (sugar carbons), $51.9\left(-\mathrm{CH}\left(\mathrm{CH}_{3}\right) \mathrm{Cl}\right), 25.8\left(-\mathrm{SiC}\left(\mathrm{CH}_{3}\right)_{3}\right), 21.2\left(-\mathrm{CH}\left(\mathrm{CH}_{3}\right) \mathrm{Cl}\right), 18.3\left(-\mathrm{SiC}\left(\mathrm{CH}_{3}\right)_{3}\right),-5.1\left(-\mathrm{Si}\left(\mathrm{CH}_{3}\right)_{2}\right)$. IR $(\mathrm{KBr}): \tilde{v}\left(\mathrm{~cm}^{-1}\right)=3449,2956,2932,2859\left(v_{\mathrm{C}-\mathrm{H}}\right), 1752\left(v_{\mathrm{C}=\mathrm{O}}\right), 1450,1382\left(v_{\mathrm{C}-\mathrm{H}}\right), 779,688\left(v_{\mathrm{C}-\mathrm{Cl}}\right)$. 


\subsection{Synthesis of Heptakis-(2,3,6-tri-O-chloropropionyl)- $\beta$-cyclodextrin (6) (21-Cl- $\beta$-CD)}

Vacuum dried $\beta$-cyclodextrin $(1.0 \mathrm{~g}(0.44 \mathrm{mmol}))$ and DMAP $(10 \mathrm{mg}(0.08 \mathrm{mmol}))$ were dissolved in anhydrous DMAc $(5 \mathrm{~mL})$ and cooled to $0{ }^{\circ} \mathrm{C}$. 2-Chloropropionyl chloride $(1.79 \mathrm{~mL}, 0.0185 \mathrm{~mol})$ was added to the solution under argon using a syringe within $1 \mathrm{~h}$. The reaction was carried out at $0{ }^{\circ} \mathrm{C}$ for $1 \mathrm{~h}$ and then at $50^{\circ} \mathrm{C}$ for 2 days. Afterwards the mixture was poured drop wise into water, the precipitate was collected, washed with water and dried in vacuo at $80^{\circ} \mathrm{C}$. The product was obtained as a pale brown solid (yield: $35 \%): m_{\mathrm{p}}=75-76^{\circ} \mathrm{C} .{ }^{1} \mathrm{H} \mathrm{NMR}\left(500 \mathrm{MHz}, \mathrm{CDCl}_{3}\right): \delta(\mathrm{ppm})=5.54-3.97(\mathrm{~m}$, sugar residues and $\left.-\mathrm{CH}\left(\mathrm{CH}_{3}\right) \mathrm{Cl}\right), 1.72\left(\mathrm{~m},-\mathrm{CH}\left(\mathrm{CH}_{3}\right) \mathrm{Cl}\right) .{ }^{13} \mathrm{C} \mathrm{NMR}\left(125 \mathrm{MHz}, \mathrm{CDCl}_{3}\right): \delta(\mathrm{ppm})=170.0-168.8(\mathrm{C}=\mathrm{O})$, 97.4-95.2, 72.8-68.6 (sugar carbons), 64.7-62.9 $\left(-\mathrm{CHCH}_{2} \mathrm{O}\right), 53.1-50.7(-\mathrm{C}-\mathrm{Cl}), 22.1-20.0\left(-\mathrm{CH}_{3}\right)$. IR $(\mathrm{KBr}): \tilde{v}\left(\mathrm{~cm}^{-1}\right)=3449,2991\left(v_{\mathrm{C}-\mathrm{H}}\right), 1753\left(v_{\mathrm{C}=\mathrm{O}}\right), 1449,1382\left(v_{\mathrm{C}-\mathrm{H}}\right), 697\left(v_{\mathrm{C}-\mathrm{Cl}}\right)$.

\subsection{Synthesis of Star-like PNIPAAm Homopolymers by ATRP}

The polymerizations were performed in DMSO [30] using initiators (4)-(6) and in AN using initiators (5) and (6). All polymerization reactions were carried out under an argon atmosphere in a Schlenk tube with a stirring bar. The general procedure for the polymerization in DMSO is described in the following.

A vacuum dried Schlenk tube was charged with NIPAAm (0.403 g (3.56 mmol)), CuCl (5.64 mg, (0.057 mmol)), $\mathrm{CuCl}_{2}(1.91 \mathrm{mg}(0.01 \mathrm{mmol}))$ and $\mathrm{Me}_{6} \mathrm{TREN}(19 \mu \mathrm{L}(0.08 \mathrm{mmol}))$. After the addition of DMSO $(1 \mathrm{~mL})$, the mixture was degassed using three freeze-pump-thaw cycles, and the solution was sealed under argon. The tube was tempered at $20^{\circ} \mathrm{C}$ and the polymerization was started by addition of the initiator $(10.0 \mathrm{mg}(0.51 \mu \mathrm{mol}))$ that was dissolved in DMSO $(0.44 \mathrm{~mL})$ via a syringe. The polymerization proceeded for $18 \mathrm{~h}$ and was stopped by cooling with liquid nitrogen and exposure to air. The solvent was removed by distillation under reduced pressure and the residue was dissolved in THF. To remove the catalyst the residue was filtrated through a plug of $\mathrm{Al}_{2} \mathrm{O}_{3}$. The resulting solution was concentrated by rotary evaporator and precipitated by addition to an excess of cold diethyl ether. After a second precipitation cycle the polymer was dialyzed against water (Spectra/Por 6, MWCO 1000). The purified colorless PNIPAAm star polymer was freeze-dried. Monomer conversion convnMr was estimated with ${ }^{1} \mathrm{H}$ NMR (see Table 1 for characterization data).

Table 1. Experimental results for the synthesis of star-like PNIPAAm homo polymers.

\begin{tabular}{ccccccccc}
\hline Sample & Initiator & $\mathbf{M} / \mathbf{I} / \mathbf{C u}(\mathbf{I}) / \mathbf{C u}(\mathbf{I I}) / \mathbf{L}^{\mathbf{a}}$ & Solvent & $\boldsymbol{T}\left({ }^{\circ} \mathbf{C}\right)$ & Time (h) & ConvNMR $(\mathbf{\%})$ & $\boldsymbol{M}_{\mathbf{n}, \mathbf{S E C}}\left(\mathbf{g} \mathbf{~ m o l}^{-\mathbf{1}}\right)$ & $\mathbf{P D}_{\mathbf{s E C}}$ \\
\hline $\mathbf{7 a}$ & $\mathbf{4}$ & $200 / 1 / 1 / 0 / 1$ & DMSO & 20 & 1.5 & 68 & 152,000 \\
$\mathbf{7 b}$ & $\mathbf{4}$ & $100 / 1 / 1.6 / 0.4 / 2$ & DMSO & 20 & 18 & 68 & 94,000 & 1.24 \\
$\mathbf{8 a}$ & $\mathbf{5}$ & $100 / 1 / 1 / 0 / 1$ & AN & 30 & 18 & 82 & 146,000 & 1.23 \\
$\mathbf{8 b}$ & $\mathbf{5}$ & $100 / 1 / 1 / 0 / 1$ & DMSO & 20 & 18 & 58 & 96,000 & 1.22 \\
$\mathbf{9 a}$ & $\mathbf{6}$ & $50 / 1 / 1 / 0 / 1$ & AN & 30 & 19 & 95 & 61,400 & 1.10 \\
$\mathbf{9 b}$ & $\mathbf{6}$ & $100 / 1 / 1.6 / 0.4 / 2$ & DMSO & 20 & 6.5 & 67 & 120,000 & 1.30 \\
$\mathbf{9 c}$ & $\mathbf{6}$ & $150 / 1 / 1 / 0 / 1$ & AN & 30 & 20 & 99 & 231,000 & 1.20 \\
\hline
\end{tabular}

${ }^{a} \mathrm{M}, \mathrm{I}, \mathrm{Cu}(\mathrm{I}), \mathrm{Cu}(\mathrm{II})$ and $\mathrm{L}$ represent the relative initial concentration of monomer, total initiation sites, $\mathrm{Cu}(\mathrm{I}) \mathrm{Cl}, \mathrm{Cu}(\mathrm{II}) \mathrm{Cl}$, and ligand. 


\subsection{Synthesis of the Star Block Copolymers}

The following synthesis protocol for a 7-arm star PNIPAAm- $b$-P(NIPAAm-co-DMAAm) block copolymer is exemplary for all other synthesis. The composition and the results of the polymerization are summarized in Table 2.

A vacuum dried Schlenk tube was charged with NIPAAm $(0.49 \mathrm{~g}$ (4 mmol)), $\mathrm{CuCl}(7 \mathrm{mg}$ $(0.07 \mathrm{mmol})), \mathrm{CuCl}_{2}(2.3 \mathrm{mg}(17 \mu \mathrm{mol}))$ and $\mathrm{Me}_{6} \mathrm{TREN}(24 \mu \mathrm{L}(0.09 \mathrm{mmol}))$. After the addition of DMSO ( $2 \mathrm{~mL})$, the mixture was immediately deoxygenated by three freeze-pump-thaw cycles, and the solution was sealed under argon. The tube was tempered at $20^{\circ} \mathrm{C}$ and the polymerization was started by addition of the initiator $(10 \mathrm{mg})$ dissolved in DMSO $(1 \mathrm{~mL})$ via a syringe. The polymerization proceeded for a certain time after which a sample was taken. Afterwards the second monomer DMAAm (2.04 mL (20 mmol)), $\mathrm{CuCl}(7 \mathrm{mg}(7 \mathrm{mmol}))$ and $\mathrm{Me}_{6}$ TREN $(24 \mu \mathrm{L}(0.09 \mathrm{mmol}))$ were dissolved in DMSO $(1 \mathrm{~mL})$, degassed using three freeze-pump-thaw cycles and added to the star-like PNIPAAm homo polymer reaction mixture in the Schlenk tube. The reaction proceeded for a certain time and was stopped by cooling with liquid nitrogen and exposure to air. The solvent was removed by distillation and the residue was dissolved in THF. To remove the catalyst the residue was filtrated through a plug of $\mathrm{Al}_{2} \mathrm{O}_{3}$. The resulting solution was concentrated by rotary evaporator and precipitated by addition to an excess of cold diethyl ether. After a second precipitation cycle the polymer was dialyzed against water (Spectra/Por 6, MWCO 1000). The purified colorless PNIPAAm star polymer was freeze-dried. All compositions applied for the synthesis of the PNIPAAm- $b$-P(NIPAAm-co-DMAAm) block copolymers are summarized in Table 2.

\subsection{Characterization}

${ }^{1} \mathrm{H}$ and ${ }^{13} \mathrm{C}$ NMR spectra were recorded at $25{ }^{\circ} \mathrm{C}$ on a Bruker "Avance 500 " spectrometer using $\mathrm{CDCl}_{3}$ or DMSO- $d_{6}$ as solvents. Electrospray Ionization Time-of Flight (ESI-ToF) mass spectra were recorded with a "SYNAPT G2-HDMS" mass spectrometer (Waters, Manchester, UK). The measurements were made in positive mode with a capillary voltage of $3 \mathrm{kV}$ and a source temperature of $120^{\circ} \mathrm{C}$. SEC measurements of the PNIPAAm homo star polymer and star block copolymers were carried out using DMAc containing $0.1 \mathrm{wt} \% \mathrm{LiBr}$ as eluent at a column temperature of $50^{\circ} \mathrm{C}$ and a flow rate of $1 \mathrm{~mL} \cdot \mathrm{min}^{-1}$. The SEC set-up consists of a Merck Hitachi 655A-11 pump (Darmstadt, Germany), three columns (particle size $10 \mu \mathrm{m}$; PSS-GRAM guard, PSS-GRAM $10^{2} \AA$, PSS-GRAM $10^{3} \AA$ ) from Polymer Standard Service (PSS) and a Knauer "Smartline RI Detector 2300" refractive index detector. As calibration poly(methyl methacrylate) standards were used. Turbidity measurements of aqueous PNIPAAm homo star polymer solutions $(0.1 \mathrm{wt} \%)$ to determine the critical temperature $T_{\mathrm{c}}$, where carried out using a Perkin Elmer "Lambda 45" UV-Vis spectrophotometer (Waltham, MA, USA) at $500 \mathrm{~nm}$. $T_{\mathrm{c}}$ was defined as the temperature corresponding to $50 \%$ decrease of optical transmittance. Micro-differential scanning calorimetry (Micro-DSC) measurements were carried out on a microDSC III from Setaram (Caluire, France). The sample solution with a concentration of $5.0 \mathrm{wt} \%$ was heated with a rate of $0.5^{\circ} \mathrm{C} / \mathrm{min}$ in the range from 5 to $60^{\circ} \mathrm{C}$. The onset value of the peak and the peak maximum, respectively, were evaluated as

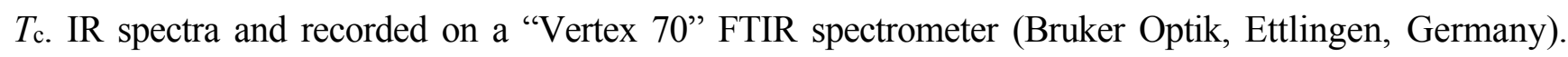
Melting points were determined with a "Melting Point B-545" apparatus (Büchi, Essen, Germany). 
Table 2. Experimental results for the synthesis of star-like PNIPAAm- $b$-P(NIPAAm-coDMAAm) block copolymers.

\begin{tabular}{cccccccc}
\hline Sample & Initiator & $\mathbf{A} / \mathbf{B} / \mathbf{I} / \mathbf{C u}(\mathbf{I}) / \mathbf{C u}(\mathbf{I I}) / \mathbf{L}^{\mathbf{a}}$ & Solvent & Time (h) & convNMR $\left._{(\mathbf{A}} \%\right)$ & Time (h) & convNMR (A \%/B \%) \\
\hline $\mathbf{1 0 a}$ & $\mathbf{4}$ & $150 / 450 / 1 / 1 / 0 / 1$ & DMSO & 2 & 62 & 20 & $70 / 24$ \\
$\mathbf{1 0 b}$ & $\mathbf{4}$ & $150 / 900 / 1 / 1 / 0 / 1$ & DMSO & 2 & 66 & 15.5 & $61 / 23$ \\
$\mathbf{1 1 a}$ & $\mathbf{5}$ & $100 / 450 / 1 / 1 / 0 / 1$ & DMSO & 2 & 53 & 19 & $57 / 24$ \\
$\mathbf{1 1 b}$ & $\mathbf{5}$ & $100 / 500 / 1 / 1 / 0 / 1$ & DMSO & 2 & 60 & 17 & $65 / 21$ \\
$\mathbf{1 1 c}$ & $\mathbf{5}$ & $100 / 1000 / 1 / 1.6 / 0.4 / 1$ & DMSO & 2.5 & 47 & 16 & $47 / 19$ \\
$\mathbf{1 2 a}$ & $\mathbf{6}$ & $150 / 440 / 1 / 2 / 0 / 2$ & AN & 7 & 64 & 17 & $64 / 12$ \\
$\mathbf{1 2 b}$ & $\mathbf{6}$ & $100 / 500 / 1 / 1.6 / 0.4 / 2$ & DMSO & 3 & 59 & 19 & $50 / 19$ \\
$\mathbf{1 2 c}$ & $\mathbf{6}$ & $100 / 1000 / 1.6 / 0.4 / 2$ & DMSO & 3.5 & 49 & 13 & $48 / 19$ \\
\hline
\end{tabular}

${ }^{a} \mathrm{~A}, \mathrm{~B}, \mathrm{I}, \mathrm{Cu}(\mathrm{I}), \mathrm{Cu}(\mathrm{II})$ and $\mathrm{L}$ represent the relative initial concentrations of NIPAAm (A), DMAAm (B), total initiation sites, $\mathrm{Cu}(\mathrm{I}) \mathrm{Cl}, \mathrm{Cu}(\mathrm{II}) \mathrm{Cl}_{2}$, and ligand.

\section{Results and Discussion}

\subsection{Synthesis of Multifunctional ATRP Initiators}

In order to prepare star polymers via ATRP it is necessary to introduce an alkyl halide end group into the core molecule. Different methods for the preparation of heptakis[2,3,6-tri-O-(2-bromo-2-methylpropionyl)]$\beta$-cyclodextrin (21-Br- $\beta$-CD) are described in literature. For example, Haddleton et al. [18] applied 2-bromoisobutyric anhydride instead of the commercially available acid halides as esterification agent and anhydrous pyridine as solvent. However, the final yield of $21-\mathrm{Br}-\beta-\mathrm{CD}$ only reached $17 \%$. Liu et al. [31] developed a simple route to synthesize the $21-\mathrm{Br}-\beta-\mathrm{CD}$ initiator through the reaction of $\beta$-CD with 2-bromoisobutyryl bromide in $N$-methyl-2-pyrrolidone (NMP). Carpov et al. [32] investigated the chloroacetylation of $\beta$-cyclodextrin in various basic media $(N, N$-dimethylacetamide (DMAc), $N, N$-dimethylformamide (DMF), NMP) and found that the highest degree of substitution (DS) with chloroacetyl groups could be achieved using DMAc. Hence, in the present work, the chloropropionyl-terminated initiator 21-Cl- $\beta-\mathrm{CD}(\mathbf{6})$ was prepared by direct esterification reaction of the hydroxyl groups at the periphery with 2-chloropropionyl chloride using DMAc as solvent.

7-Cl- $\beta$-CD (4) and 14-Cl- $\beta-C D$ (5) were obtained in a multi-step synthesis strategy using tert-butyldimethylsilyl chloride (TBDMSCl) and methyl iodide as regioselective protection agents. Due to the different reactivity of the primary and secondary hydroxyl groups within $\beta$-CD it is possible to selectively convert only the seven primary hydroxyl groups into TBDMS ether groups. Afterwards the secondary hydroxyl groups of (1) were treated with 2-chloropropionyl chloride to get the multifunctional initiator (5). The esterification reaction is accompanied by $\mathrm{HCl}$ release, which might result in the deprotection of the acid-labile TBDMS protecting groups. According to Li et al. [33] who investigated the effect of $\mathrm{pH}$ and temperature on the formation of per-6-(tert-butyldimethylsilyl)oxy-2,3-di- $O$ chloroacetyl- $\beta-C D$ imidazole was added to the reaction mixture. They have shown that imidazole is an appropriate proton scavenger to control the $\mathrm{pH}$ of the system and with its use all hydroxyl groups remained protected. In our case the seven hydroxyl groups remained protected if a $\mathrm{pH}$ value of 8 and a temperature of $50{ }^{\circ} \mathrm{C}$ was maintained. To generate the multifunctional initiator (4) first the secondary hydroxyl groups of heptakis-(6-(tert-butyldimethylsilyl)oxy)- $\beta$-cyclodextrin (1) had to be methylated 
using a large excess of MeI and oil-free $\mathrm{NaH}$ in dry THF at room temperature. Desilylation of (2) was accomplished with tetra- $n$-butylammonium fluoride solution. Finally, the non-protected primary hydroxyl groups were esterified with 2-chloropropionyl chloride. The structure of the initiators could be proven by NMR (Scheme 1) and FTIR spectroscopy as well as ESI-ToF-MS. The detailed pathway for the synthesis of the multifunctional ATRP initiators is shown in Scheme 2.

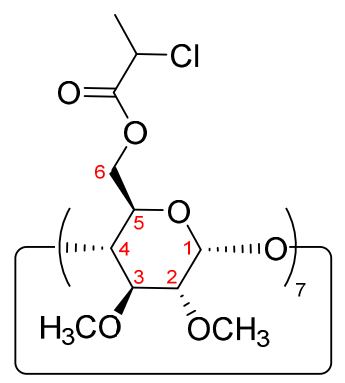

Scheme 1. Assignment of NMR signals for CD initiator (4).

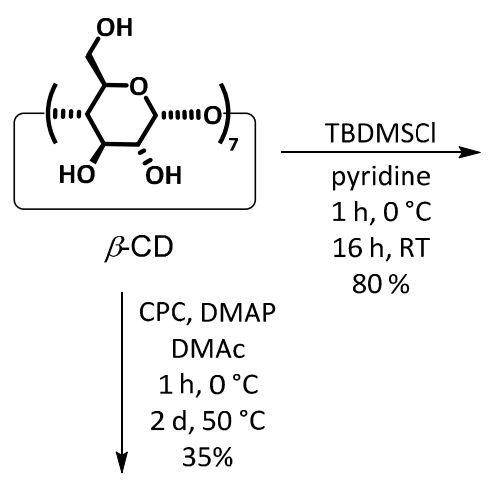

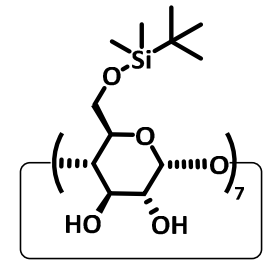

(1)

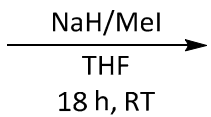

$62 \%$

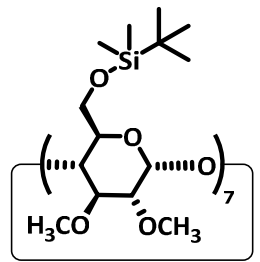

(2)

$$
\begin{array}{|c|c}
\text { CPC, imidazole, DMAP } & 1 \mathrm{~N} \mathrm{TBAF} \\
\text { DMAc } & \text { THF } \\
1 \mathrm{~h}, 0^{\circ} \mathrm{C} & 12 \mathrm{~h}, 66^{\circ} \mathrm{C} \\
3 \mathrm{~d}, 50^{\circ} \mathrm{C} & 76 \% \\
48 \% & \downarrow
\end{array}
$$

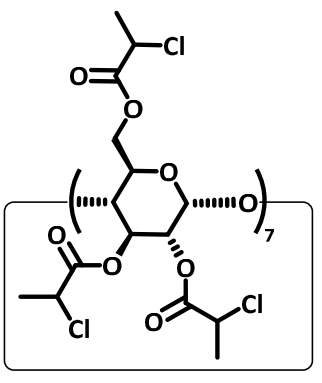

$21-\mathrm{Cl}-\beta-\mathrm{CD}$

(6)

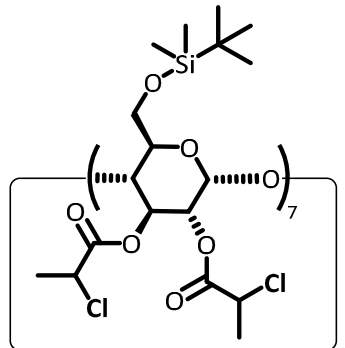

$14-\mathrm{Cl}-\beta-\mathrm{CD}$

(5)

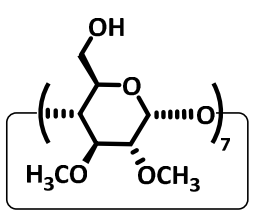

(3)

CPC, DMAP DMAC

$1 \mathrm{~h}, 0^{\circ} \mathrm{C}$ $3 \mathrm{~d}, 50^{\circ} \mathrm{C}$

$\downarrow \quad 28 \%$

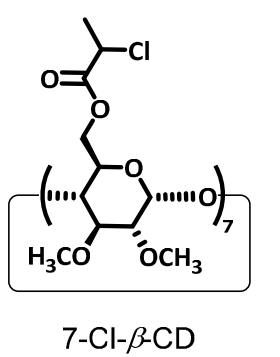

(4)

Scheme 2. Synthesis of the $\beta$-Cyclodextrin based Initiators 7-Cl- $\beta$-CD (4), $14-C 1-\beta-C D(5)$ and 21-C- $\beta-C D(6)$. 


\subsection{Synthesis of 7-Arm, 14-Arm and 21-Arm Star-like PNIPAAm Homo Polymers}

The modified $\beta$-cyclodextrins (4)-(6) were used in a further step as initiators for the copper(I)-mediated ATRP of $N$-isopropylacrylamide (NIPAAm) (Scheme 3) via the "core-first" method. A few conditions for the controlled polymerization of NIPAAm are known [34]. In most of the cases, polar solvents like water or aqueous DMF or isopropanol have to be used. Due to the poor solubility of the initiators in aqueous solutions, new conditions had to be established. Based on model reactions of pentaerythritoltetrakis-(2-bromoisobutyrate) and pentaerythritol-tetrakis-(2-chloropropionate), respectively, suitable conditions could be found. For a number of solvents (water, toluene, isopropanol, and acetonitrile (AN)) it turned out that the bromo-initiator did not yield any polymer. The chloro-initiator worked much better, e.g., in $\mathrm{AN}$ with $\mathrm{CuCl} / \mathrm{Me} 6 \mathrm{TREN}$ as catalyst. Maynard et al. [30] performed kinetic studies with a biotin bearing initiator in deuterated $\mathrm{DMSO}$. The addition of $\mathrm{CuCl}_{2}$ shifted the equilibrium towards the dormant species and improved the control of the polymerization. The loss of control in aqueous ATRP systems is caused by different side reactions [35]. Mainly hydrolysis of the deactivator takes place causing a decrease of the deactivation rate and, hence, an increase of the speed of reaction as well as a loss of control. Br- $\beta$-CD ATRP initiators have been used in pure water at $60{ }^{\circ} \mathrm{C}$ yielding PNIPAAm stars with polydispersities of 1.60 to 4.04 [25]. This might be due to star-star coupling reactions, which are enhanced since the polymerization temperature was above $T_{\mathrm{c}}$ causing a collapse of the growing chains. Hence, the polymerization was performed in AN and DMSO, respectively, at moderate temperature with $\mathrm{CuCl} / \mathrm{Me}_{6} \mathrm{TREN}$ as catalytic system. Seven star-like PNIPAAm homo polymers with different arm numbers and arm lengths were synthesized as summarized in Table 1. All PNIPAAm stars could be obtained under controlled conditions and with narrow polydispersities. SEC traces of selected samples are shown in Figure 1.

Polymerization kinetics were determined for 7-Cl- $\beta-\mathrm{CD}, 14-\mathrm{Cl}-\beta-\mathrm{CD}, 21-\mathrm{Cl}-\beta-\mathrm{CD}$ with $[\mathrm{M}] /[\mathrm{I}]$ ratios of 700, 1400 and 2100, corresponding to 100 moles of monomer per one mole of initiating sites. For all three initiators the molar ratio of $[\mathrm{I}] /[\mathrm{CuCl}] /\left[\mathrm{CuCl}_{2}\right] /\left[\mathrm{Me}_{6} \mathrm{TREN}\right]$ was $[1] /[1.6] /[0.4] /[2]$. All reactions were carried out in DMSO at $20{ }^{\circ} \mathrm{C}$ and samples were taken during the polymerization in order to determine the molecular weight and polydispersity using SEC and the monomer conversion with ${ }^{1} \mathrm{H}$ NMR.

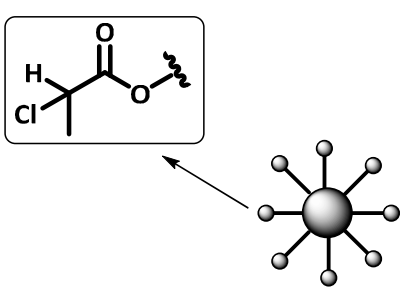

(4)-(6)

multifunctional initiator

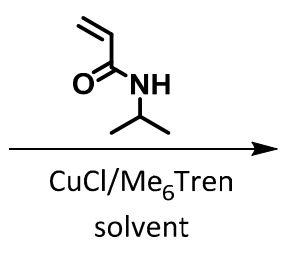

solvent

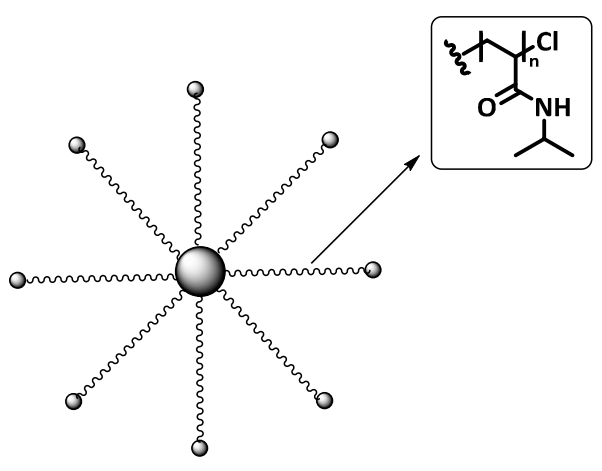

(7)

star-like PNIPAAm homo polymer

Scheme 3. Synthesis of star-like PNIPAAm homo polymers using ATRP. 


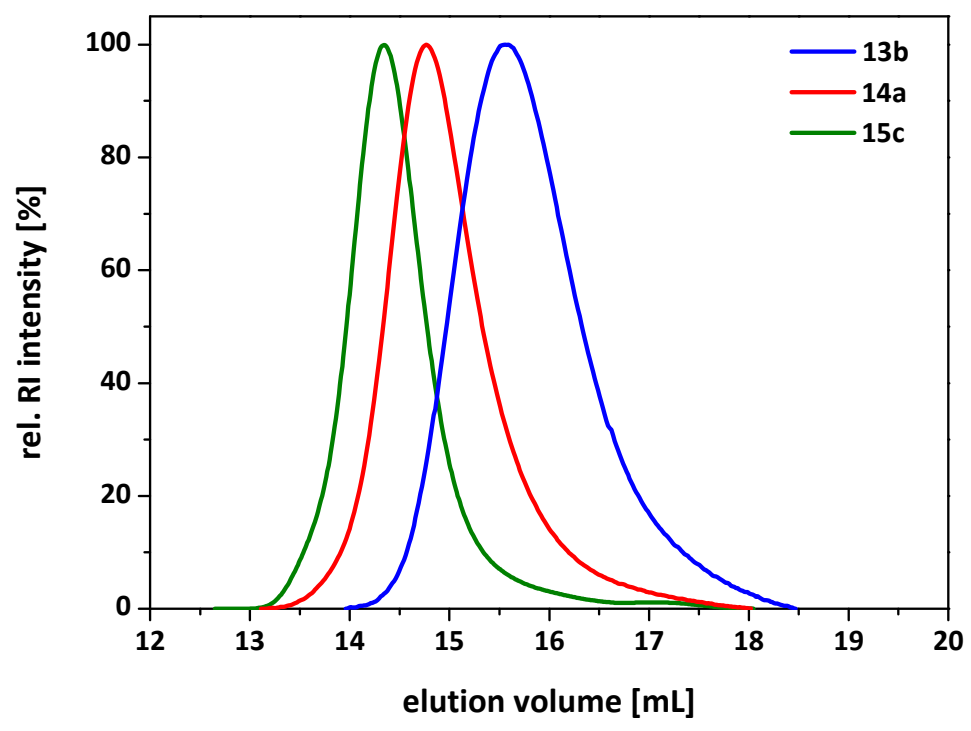

Figure 1. SEC traces of selected PNIPAAm star homo polymers.

The plots of $\ln \left([\mathrm{M}]_{0} /[\mathrm{M}]_{\mathrm{t}}\right)$ versus time increased linearly, indicating that the concentration of the radicals remains constant during polymerization (Figure 2). The polymerization followed first order kinetics, and after $6 \mathrm{~h}$, conversions above $60 \%$ could be obtained. However, at the beginning of the reaction, relatively high conversions were obtained. Nevertheless, these first polymers show narrow polydispersities as well. It has to be pointed out that further evaluation of the kinetic data is difficult. SEC data are not reliable since linear standards were compared with branched structures. Additionally, due to the high molecular weight signals of the end groups in ${ }^{1} \mathrm{H}$ NMR spectra could not be observed.

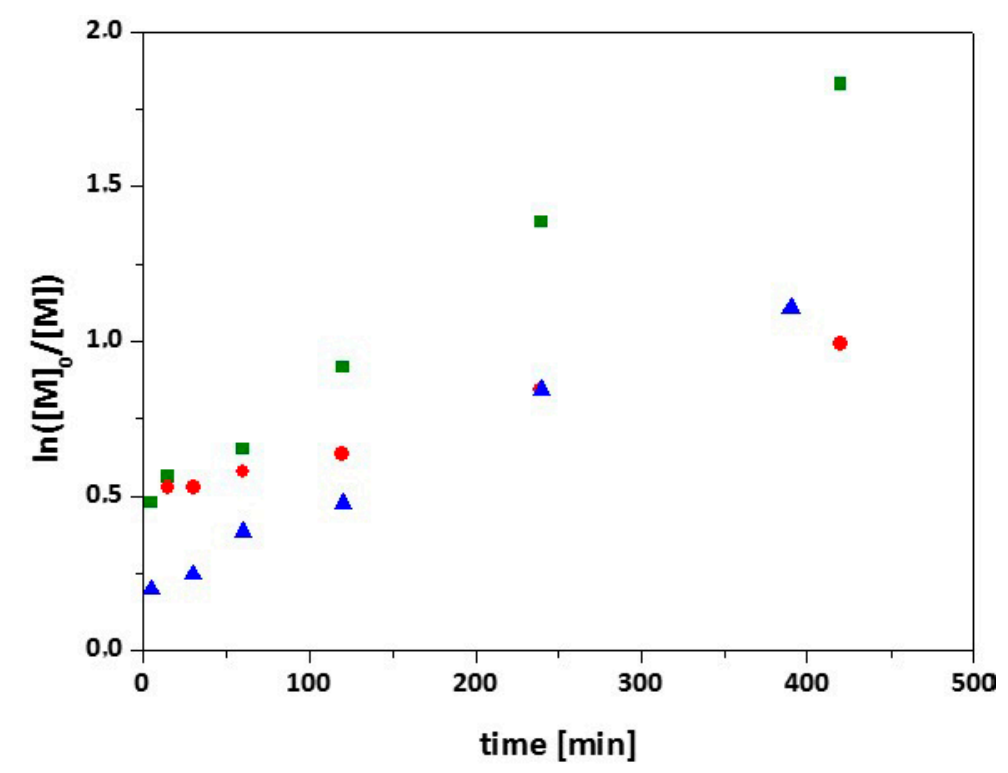

Figure 2. Kinetic plots for the polymerization of NIPAAm in DMSO at $20{ }^{\circ} \mathrm{C}$ using

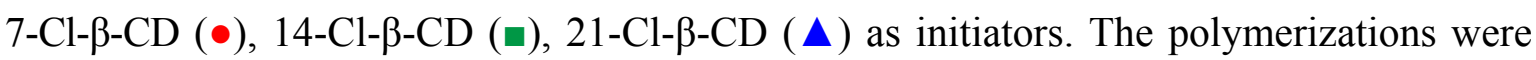
performed using 100 moles of monomer per one mole of initiating sites (corresponding to $[\mathrm{M}] /[\mathrm{I}]$ ratios of 700,1400 and 2100 , respectively). The molar ratio of $[\mathrm{I}] /[\mathrm{CuCl}] /[\mathrm{CuCl} 2] /[\mathrm{Me} 6 \mathrm{TREN}]$ was kept at $[1] /[1.6] /[0.4] /[2]$ and the reactions were carried out in DMSO at $20{ }^{\circ} \mathrm{C}$. 


\subsection{Synthesis of 7-Arm, 14-Arm and 21-Arm Star-like PNIPAAM-b-PDMAAm Diblock Copolymers}

In order to prepare star block copolymers, one can use macroinitiators or the method of sequential monomer addition. It turned out that PNIPAAm macroinitiators were not active anymore [34]. A reason might be the loss of halogen end groups during workup. An important prerequisite for the latter case is that both monomers can be polymerized under almost the same conditions. It is also important to determine the correct time to add the second monomer to maintain active end groups. Hence, a time where the polymerization still proceeds is suitable.

Teodorescu et al. [36] investigated the ATRP of different (meth)acrylamides including DMAAm. They used methyl-2-bromopropionate, $\mathrm{Cu}(\mathrm{I}) \mathrm{Br}$ and $\mathrm{Me}$ ccyclam in methanol. The polymerization was quick but not controlled at RT and conversions higher than $65 \%$ could not be obtained. The authors gave three reasons for the loss of control. First, a deactivation of the copper catalyst might occur due to competing interactions of the amide groups of the polymer. Further, the strong bond of the bromine atom with the terminal monomer unit might decrease the ATRP equilibrium constant. Third, due to a nucleophilic attack of the second last monomer unit the halogen atom might be substituted. Either the oxygen or the nitrogen atom can attack the dormant chain end forming a five-membered ring that cannot be activated by the transition metal complex. Polar solvents and higher temperatures enhance this reaction. Rademacher et al. [37] performed systematic studies of the DMAAm polymerization. They showed by mass spectrometric studies that the loss of control can be attributed to the loss of the halogen end groups. These findings are in accordance with our results for the NIPAAm polymerization. Later the controlled polymerization of DMAAm using methyl-2-chloropropionate, $\mathrm{Cu}(\mathrm{I}) \mathrm{Cl}$ and $\mathrm{Me}_{6}$ TREN in toluene was reported [38]. PDMAAm with a degree of polymerization up to 530 and a polydispersity in the range of 1.05-1.13 could be obtained [39]. For high conversions SEC traces showed a weak tailing in the range of lower molecular weights indicating that still some termination reactions are present. Based on the results of the NIPAAm polymerization AN and DMSO can be used for the sequential monomer addition only. Unfortunately, polymerizations in AN proceeded with low yield only. Hence, all block copolymer formations were performed in DMSO.

A series of star-like PNIPAAm- $b$-PDMAAm diblock copolymers with a PNIPAAm core and a PDMAAm shell was prepared using consecutive ATRP (Scheme 4). Thus, the second monomer and new copper(I)complex were added to the star-like PNIPAAm homo polymer reaction mixture after a specific reaction time (Table 2). In order to avoid the loss of the halide end group and to suppress side reactions such as bimolecular termination, which might be an intermolecular (star-star coupling) or an intramolecular reaction (between two radicals within the star polymer), the polymerization of the first block was limited to $50 \%-60 \%$ conversion. Since the polymerization of NIPAAm cannot be driven to high conversions, the formed second block consisted in most cases of a random copolymer of DMAAm and NIPAAm. The composition of the second block can be calculated by determining the conversion of NIPAAm before and after the reaction with DMAAm. Figure 3 shows the ${ }^{1} \mathrm{H}$ NMR spectra of a resulting reaction mixture. The blue cycled peaks at $5.54 \mathrm{ppm}$ can be attributed to one vinylic proton of NIPAAm, whereas the broad peak in the range of 3.97-3.75 ppm can be assigned to the isopropyl proton of the monomer and polymer. The green cycled peaks at $5.65 \mathrm{ppm}$ can be assigned to a vinylic proton of DMAAm, whereas the peak in the range of 3.15-2.66 ppm can be attributed to the methyl groups of the monomer and polymer. The conversion convmon can be calculated by Equation (1): 


$$
\operatorname{conv}_{\text {mon }}=\frac{I_{M+P}-I_{M}}{I_{M+P}}
$$

with $I_{M+P}$ as the integral of the monomer and polymer signal and $I_{M}$ as theintegral of the monomer only. The results are summarized in Table 2. As can be seen from Table 2, the reactivity of DMAAm is much higher than NIPAAm. Hence, the second block did not contain more than approximately $10 \%$ of NIPAAm. A typical SEC trace for the two polymers is shown in Figure 4 proving block copolymer formation. However, the tailing towards higher elution volume indicates that there were termination reactions present at the end of the first step or/and after the addition of the second monomer. Table 3 summarizes the results of the block copolymer formation.

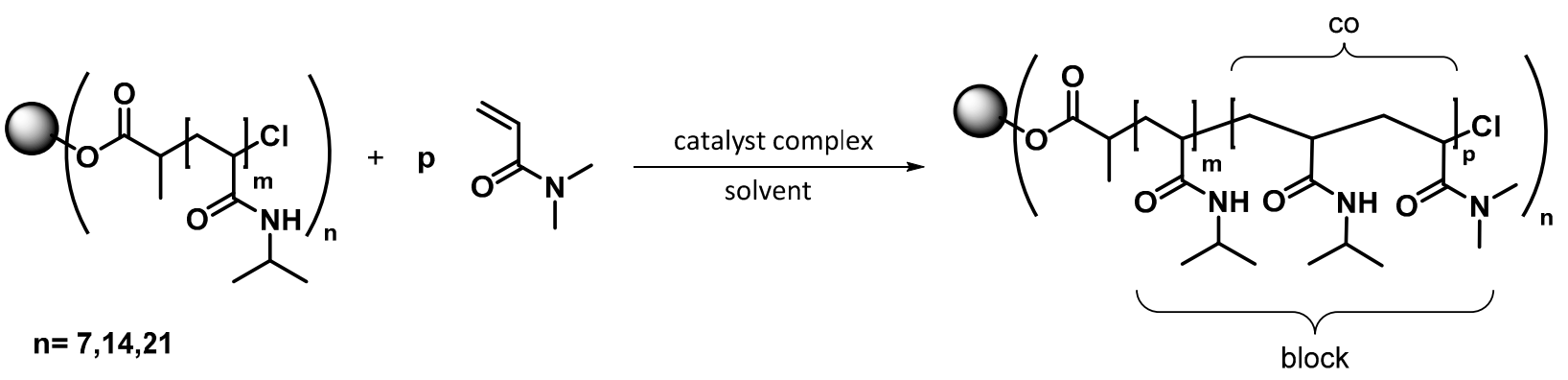

Scheme 4. Formation of star block copolymers by sequential monomer addition.

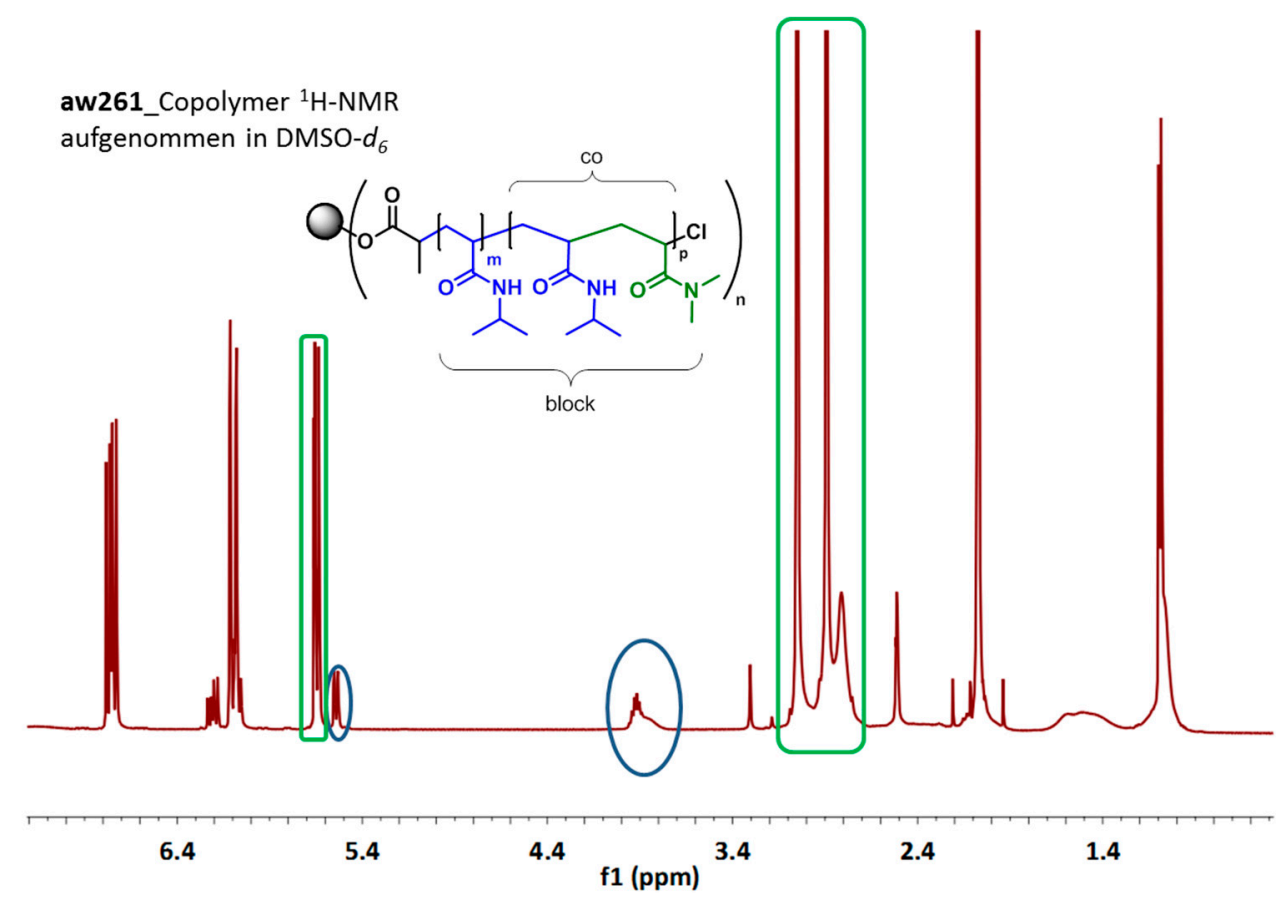

Figure 3. ${ }^{1} \mathrm{H}$ NMR spectra of a resulting reaction mixture after block copolymer formation by sequential monomer addition. Blue framed signals represent NIPAAm and PNIPAAm, respectively, whereas, green framed signal represent DMAAm and PDMAAm, respectively. 


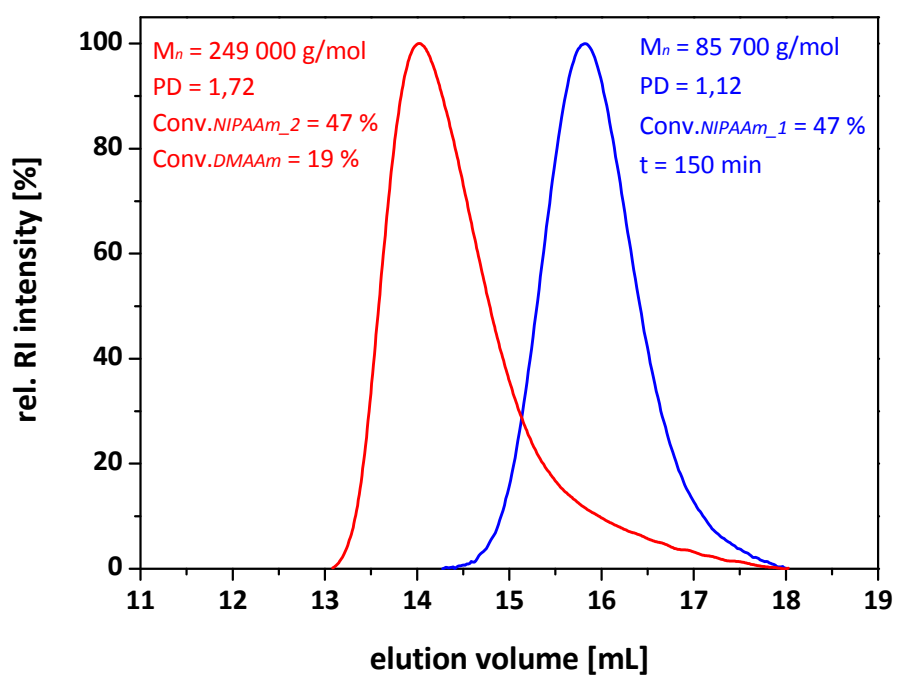

Figure 4. SEC traces of star block copolymer formation of 11c (PNIPAAm homo polymer (blue) and PNIPAAm-PDMAAm block copolymer (red)).

Table 3. Results of the SEC-characterization of star-like PNIPAAm- $b-\mathrm{P}(\mathrm{NIPAAm}-c o$ DMAAm) diblock copolymers.

\begin{tabular}{ccccccc}
\hline Sample & Initiator & $\boldsymbol{M}_{\mathbf{n}, \mathbf{S E C}}(\mathbf{g} / \mathbf{m o l})$ & PDSEC & $\boldsymbol{M}_{\mathbf{n}, \mathbf{S E C}}(\mathbf{g} / \mathbf{m o l})$ & PDSEC & Polymer Composition $^{\text {a,b }}$ \\
\hline $\mathbf{1 0 a}$ & $\mathbf{4}$ & 143,000 & 1.33 & 189,000 & 1.77 & $\mathrm{~A}_{93}-b-\left(\mathrm{A}_{12}-c o-\mathrm{B}_{108}\right)$ \\
$\mathbf{1 0 b}$ & $\mathbf{4}$ & 138,000 & 1.21 & 161,000 & 1.85 & $\mathrm{~A}_{99}-c o-\mathrm{B}_{207}$ \\
$\mathbf{1 1 a}$ & $\mathbf{5}$ & 81,000 & 1.19 & 153,000 & 1.62 & $\mathrm{~A}_{74-b}-\mathrm{B}_{99}$ \\
$\mathbf{1 1 b}$ & $\mathbf{5}$ & 120,000 & 1.14 & 161,000 & 1.56 & $\mathrm{~A}_{60}-b-\left(\mathrm{A}_{5}-c o-\mathrm{B}_{189}\right)$ \\
$\mathbf{1 1 c}$ & $\mathbf{5}$ & 85,700 & 1.12 & 249,000 & 1.72 & $\mathrm{~A}_{47}-b-\mathrm{B}_{190}$ \\
$\mathbf{1 2 a}$ & $\mathbf{6}$ & 192,000 & 1.31 & 254,000 & 1.35 & $\mathrm{~A}_{96}-b-\mathrm{B}_{50}$ \\
$\mathbf{1 2 b}$ & $\mathbf{6}$ & 124,000 & 1.15 & 209,000 & 1.70 & $\mathrm{~A}_{60}-b-\mathrm{B}_{95}$ \\
$\mathbf{1 2 c}$ & $\mathbf{6}$ & 121,000 & 1.16 & 272,000 & 1.99 & $\mathrm{~A}_{49}-b-\mathrm{B}_{190}$ \\
\hline
\end{tabular}

${ }^{\mathrm{a}} \mathrm{A}$ and B refer to NIPAAm and DMAAm, respectively; ${ }^{\mathrm{b}}$ The composition of NIPAAm and DMAAm was estimated by ${ }^{1}$ H-NMR-Spectroscopy.

\subsection{Thermal Phase Transition Behavior of Star-like PNIPAAm Homo Polymers}

Phase transition temperatures of PNIPAAm depends on end groups and molecular weight [24]. It is well known that the presence of hydrophobic end groups decreases the phase transition temperature of PNIPAAm polymers [40]. For example, Figure 5 shows the transmittance curves plotted against the temperature for star-like PNIPAAm homo polymer aqueous solutions $\mathbf{7 b}, \mathbf{8 a}, \mathbf{9 b}$ with different arm numbers but nearly the same arm lengths. All transitions were sharp. $T_{\mathrm{c}}$ was defined as $50 \%$ transmittance. The values for the critical phase transition temperatures $T_{c}$ for star polymers are summarized in Table 4 . The $T_{\mathrm{c}}$ values for the star polymers with 7, 14 and 21 arms were in the same range and correlate to the literature value of $32{ }^{\circ} \mathrm{C}$ for high molecular weight linear PNIPAAm [41,42]. 


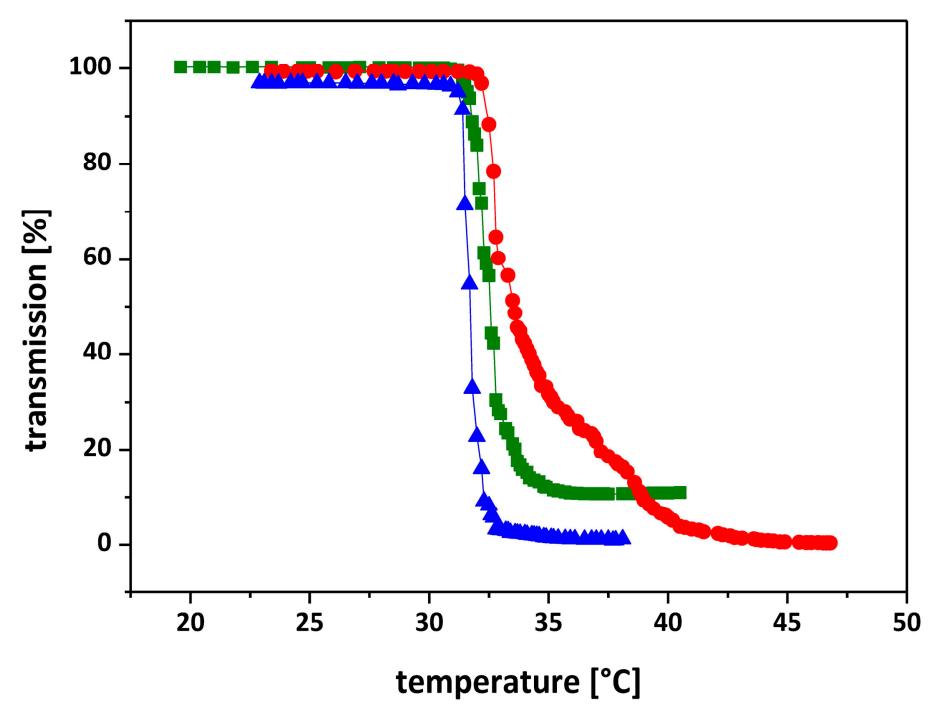

Figure 5. Transmittance curves of the star-like PNIPAAm homo polymers $7 \mathbf{b}$ (from $7-\mathrm{Cl}-\beta-\mathrm{CD}(\mathbf{\Delta}))$, $\mathbf{8 a}$ (from $14 \mathrm{Cl}-\beta-\mathrm{CD}(\bullet))$ and $\mathbf{9 b}($ from $21 \mathrm{Cl}-\beta-\mathrm{CD}(\boldsymbol{\square})$ ) in aqueous solution $(0.1 \mathrm{wt} \%)$.

The $\beta$-CD-(PNIPAAm) 21 star polymers 9a-c with varying molecular weights had a $T_{\mathrm{c}}$ of $32.5{ }^{\circ} \mathrm{C}$, $31.2{ }^{\circ} \mathrm{C}$ and $31.8^{\circ} \mathrm{C}$. All $T_{\mathrm{c}}$ values were within the same range and independent from molecular weight. This discovery agreed with the observations from Whittaker and coworkers [43]. They reported that the LCST transitions of a four arm star PNIPAAm based on a pentaerythritol moiety were depressed by the presence of the hydrophobic star core. Nevertheless, this effect was molecular weight-dependent and diminished when the number of repeating units per arm exceeded 70. In that case, the $T_{\mathrm{c}}$ was close to the literature value reported for high molecular weight linear PNIPAAm.

Star block copolymers consisting of an inner temperature-responsive PNIPAAm block and an outer non-responsive PDMAAm block will form micelle-like aggregates with increasing temperatures above $T_{\mathrm{c}}$. The formed particles consist of a core of collapsed PNIPAAm stabilized by a shell of still hydrophilic PDMAAm. This shell prevents the particles from precipitating. Hence, turbidity measurements are no longer suitable to determine $T_{\mathrm{c}}$ and DSC was used instead.

$T_{\mathrm{c}}$ values of different star block copolymers are summarized in Table 4 . $T_{\mathrm{c}}$ values from turbidimetry were obtained at the maximum change of turbidity (50\% transmittance). Thus, these values correlate well with the peak maximum values from DSC. The DSC peaks were rather flat. Hence, the determination of the onset value was quite difficult. A reason for this might be the increased sterical hindrance of the chains causing a broadening of the transition.

The length of the PDMAAm block did not have a remarkable influence on $T_{\mathrm{c}}$. The same was observed for the PNIPAAm block. Nyström et al. reported on the correlation of polymer length with $T_{\mathrm{c}}$ for PNIPAAm [44]. With increase of the number of repeating units from 47 to $71, T_{\mathrm{c}}$ decreased from 36.9 to $32.2{ }^{\circ} \mathrm{C}$. As an explanation it was claimed that there is increased hydrophobic interaction with increased degree of polymerization causing aggregation at lower temperatures. $\beta$-CD based star polymers have degrees of polymerization for each arm of 49 to 99 . This is already in a range where $T_{\mathrm{c}}$ is independent on molecular weight. 
Table 4. Critical phase transition temperatures $T_{\mathrm{c}}$ of the star-like PNIPAAm homo polymers in aqueous solution.

\begin{tabular}{cccc}
\hline Sample & Composition of Arms $^{\mathbf{a}}$ & $\boldsymbol{T}_{\mathbf{c}}\left({ }^{\circ} \mathbf{C}\right) \mathbf{U V}-\mathbf{V i s}{ }^{\mathbf{b}}$ & $\boldsymbol{T}_{\mathbf{c}}\left({ }^{\circ} \mathbf{C}\right) \mathbf{D S C}^{\mathbf{c}}$ \\
\hline $\mathbf{7 b}$ & $\mathrm{A}_{68}$ & 32.0 & - \\
$\mathbf{8 a}$ & $\mathrm{A}_{88}$ & 33.5 & - \\
$\mathbf{9 a}$ & $\mathrm{A}_{48}$ & 32.5 & - \\
$\mathbf{9 b}$ & $\mathrm{A}_{67}$ & 31.2 & - \\
$\mathbf{9 c}$ & n.d. & 31.8 & - \\
$\mathbf{1 0 a}$ & $\mathrm{A}_{93}-b-\left(\mathrm{A}_{12}-c o-\mathrm{B}_{108}\right)$ & - & $21.9(31.3)$ \\
$\mathbf{1 0 b}$ & $\mathrm{A}_{99}-b-\mathrm{B}_{207}$ & - & $23.0(31.8)$ \\
$\mathbf{1 1 b}$ & $\mathrm{A}_{60}-b-\left(\mathrm{A}_{5}-c o-\mathrm{B}_{189}\right)$ & - & $19.6(30.7)$ \\
$\mathbf{1 1 c}$ & $\mathrm{A}_{47}-b-\mathrm{B}_{190}$ & - & $24.6(32.6)$ \\
$\mathbf{1 2 a}$ & $\mathrm{A}_{96}-b-\mathrm{B}_{50}$ & - & $31.0(33.2)$ \\
$\mathbf{1 2 b}$ & $\mathrm{A}_{60}-b-\mathrm{B}_{95}$ & - & $21.9(32.8)$ \\
$\mathbf{1 2 c}$ & $\mathrm{A}_{49}-b-\mathrm{B}_{190}$ & - & $22.8(31.8)$ \\
\hline
\end{tabular}

a Determined by ${ }^{1} \mathrm{H}$ NMR; ${ }^{\mathrm{b}}$ The critical phase transition temperature $T_{\mathrm{c}}$ was determined by turbidity measurement $\left(0.1 \mathrm{wt} \%\right.$ aqueous solution) at a wavelength of $500 \mathrm{~nm}$. $T_{\mathrm{c}}$ was defined as the temperature corresponding to $50 \%$ decrease of optical transmittance; ${ }^{\mathrm{c}}$ The critical phase transition temperature $T_{\mathrm{c}}$ was determined by DSC measurement ( $5.0 \mathrm{wt} \%$ aqueous solution) at a heating rate of $0.5 \mathrm{~K} / \mathrm{min}$. $T_{\mathrm{c}}$ can be defined either as the onset temperature or the temperature at peak maximum (values in brackets).

\section{Conclusions}

PNIPAAm-PDMAAm star block copolymers can be prepared by ATRP. Starting with $\beta$-CD with 7 , 14 and 21 initiating sites, NIPAAm can be polymerized under controlled conditions. In order to prepare block copolymers, the sequential monomer addition method must be used. However, tailoring the blocks was rather difficult. Due to possible star-star coupling, which is more probable at higher conversions, conversions have to be kept below 50\%. The best time to add DMAAm was determined by kinetic experiments. The obtained block copolymers showed transition temperatures, which were almost independent of the number of arms and the composition.

\section{Author Contributions}

Agnes Wycisk performed the overall experimental work and contributed to the writing of the manuscript. Artjom Döring and Martin Schneider interpreted the results and contributed to the writing of the manuscript. Monika Schönhoff was responsible for the $\mu$ DSC measurements. Dirk Kuckling coordinated the study and contributed to the writing of the manuscript.

\section{Conflicts of Interest}

The authors declare no conflict of interest.

\section{References}

1. Kuckling, D.; Wycisk, A. Stimuli-responsive star polymers. J. Polym. Sci. A Polym. Chem. 2013, 51, 2980-2994. 
2. Hadjichristidis, N.; Pitsikalis, M.; Pispas, S.; Iatrou, H. Polymers with complex architecture by living anionic polymerization. Chem. Rev. 2001, 101, 3747-3792.

3. Miura, Y.; Dairoku, M. Synthesis and characterization of 6- and 12-arm star polymers by nitroxide-mediated radical polymerization of St and MA from dendritic TIPNO-based hexafunctional and dodecafunctional macroinitiators. J. Polym. Sci. A Polym. Chem. 2007, 45, 4364-4376.

4. Hawker, C.J. Architectural control in "living" free radical polymerizations: Preparation of star and graft polymers. Angew. Chem. Int. Ed. Engl. 1995, 34, 1456-1459.

5. Chong, B.Y.K.; Le, T.P.T.; Moad, G.; Rizzardo, E.; Thang, S.H. A more versatile route to block copolymers and other polymers of complex architecture by living radical polymerization: The RAFT process. Macromolecules 1999, 32, 2071-2074.

6. Liu, J.; Tao, L.; Xu, J.; Jia, Z.; Boyer, C.; Davis, T.P. RAFT controlled synthesis of six-armed biodegradable star polymeric architectures via a "core-first" methodology. Polymer 2009, 50, 4455-4463.

7. Kamigaito, M.; Ando, T.; Sawamoto, M. Metal-catalyzed living radical polymerization. Chem. Rev. 2001, 101, 3689-3745.

8. Tsarevsky, N.V.; Matyjaszewski, K. "Green” atom transfer radical polymerization: From process design to preparation of well-defined environmentally friendly polymeric materials. Chem. Rev. 2007, 107, 2270-2299.

9. Zhang, X.; Xia, J.; Matyjaszewski, K. End-functional poly(tert-butyl acrylate) star polymers by controlled radical polymerization. Macromolecules 2000, 33, 2340-2345.

10. Ohno, S.; Gao, H.; Cusick, B.; Kowalewski, T.; Matyjaszewski, K. Methacryloyl and/or hydroxyl end-functional star polymers synthesized by ATRP using the arm-first method. Macromol. Chem. Phys. 2009, 210, 421-430.

11. Gao, H.; Matyjaszewski, K. Synthesis of star polymers by a combination of ATRP and the "click" coupling method. Macromolecules 2006, 39, 4960-4965.

12. Altintas, O.; Yankul, B.; Hizal, G.; Tunca, U. A3-type star polymers via click chemistry. J. Polym. Sci. A Polym. Chem. 2006, 44, 6458-6465.

13. Matyjaszewski, K.; Miller, P.J.; Pyun, J.; Kickelbick, G.; Diamanti, S. Synthesis and characterization of star polymers with varying arm number, length, and composition from organic and hybrid inorganic/organic multifunctional initiators. Macromolecules 1999, 32, 6526-6535.

14. Angot, S.; Murthy, K.S.; Taton, D.; Gnanou, Y. Atom transfer radical polymerization of styrene using a novel octafunctional initiator: Synthesis of well-defined polystyrene stars. Macromolecules 1998, 31, 7218-7225.

15. Lecolley, F.; Waterson, C.; Carmichael, A.J.; Mantovani, G.; Harrisson, S.; Chappell, H.; Limer, A.; Williams, P.; Ohno, K.; Haddleton, D.M. Synthesis of functional polymers by living radical polymerization. J. Mater. Chem. 2003, 13, 2689-2695.

16. Strandman, S.; Tenhu, H. Star polymers synthesised with flexible resorcinarene-derived ATRP initiators. Polymer 2007, 48, 3938-3951.

17. Haddleton, D.M.; Waterson, C. Phenolic ester-based initiators for transition metal mediated living polymerization. Macromolecules 1999, 32, 8732-8739.

18. Ohno, K.; Wong, B.; Haddleton, D.M. Synthesis of well-defined cyclodextrin-core star polymers. J. Polym. Sci. A Polym. Chem. 2001, 39, 2206-2214. 
19. Karaky, K.; Reynaud, S.; Billon, L.; François, J.; Chreim, Y. Organosoluble star polymers from a cyclodextrin core. J. Polym. Sci. A Polym. Chem. 2005, 43, 5186-5194.

20. Adeli, M.; Zarnegar, Z.; Kabiri, R. Amphiphilic star copolymers containing cyclodextrin core and their application as nanocarrier. Eur. Polym. J. 2008, 44, 1921-1930.

21. Pang, X.; Zhao, L.; Akinc, M.; Kim, J.K.; Lin, Z. Novel amphiphilic multi-arm, star-like block copolymers as unimolecular micelles. Macromolecules 2011, 44, 3746-3752.

22. Gou, P.-F.; Zhu, W.-P.; Xu, N.; Shen, Z.-Q. Synthesis and self-assembly of well-defined cyclodextrin-centered amphiphilic $\mathrm{A}_{14} \mathrm{~B}_{7}$ multimiktoarm star copolymers based on poly( $\varepsilon$-caprolactone) and poly(acrylic acid). J. Polym. Sci. A Polym. Chem. 2010, 48, 2961-2974.

23. Döring, A.; Birnbaum, W.; Kuckling, D. Responsive hydrogels - Structurally and dimensionally optimized smart frameworks for applications in catalysis, micro-system technology and material science. Chem. Soc. Rev. 2013, 42, 7391-7420.

24. Xu, J.; Liu, S. Synthesis of well-defined 7-arm and 21-arm poly( $N$-isopropylacrylamide) star polymers with $\beta$-cyclodextrin cores via click chemistry and their thermal phase transition behavior in aqueous solution. J. Polym. Sci. A Polym. Chem. 2009, 47, 404-419.

25. Mauricio, M.R.; Otsuka, I.; Borsali, R.; Petzhold, C.L.; Cellet, T.S.P.; de Carvalho, G.M.; Rubira, A.F. Synthesis of star poly $(N$-isopropylacrylamide) by $\beta$-cyclodextrin core initiator via ATRP approach in water. React.Func. Polym. 2011, 71, 1160-1165.

26. Ciampolini, M.; Nardi, N. Five-coordinated high-spin complexes of bivalent cobalt, nickel, and copper with tris(2-dimethylaminoethyl)amine. Inorg. Chem. 1966, 5, 41-45.

27. Zhang, P.; Ling, C.C.; Coleman, A.W.; Parrot-Lopez, H.; Galons, H. Formation of amphiphilic cyclodextrins via hydrophobic esterification at the secondary hydroxyl face. Tetrahedron Lett. 1991, 32, 2769-2770.

28. Ashton, P.R.; Königer, R.; Stoddart, J.F. Amino acid derivatives of $\beta$-cyclodextrin. J. Org. Chem. 1996, 61, 903-908.

29. Takeo, K.; Mitoh, H.; Uemura, K. Selective chemical modification of cyclomalto-oligosaccharides via tert-butyldimethylsilylation. Carbohydr. Res. 1988, 187, 203-221.

30. Bontempo, D.; Li, R.C.; Ly, T.; Brubaker, C.E.; Maynard, H.D. One-step synthesis of low polydispersity, biotinylated poly( $N$-isopropylacrylamide) by ATRP. Chem. Commun. 2005, 4702-4704.

31. Li, J.; Xiao, H. An efficient synthetic-route to prepare [2,3,6-tri-O-(2-bromo-2-methylpropionyl]$\beta$-cyclodextrin). Tetrahedron Lett. 2005, 46, 2227-2229.

32. Carpov, A.; Mocanu, G.; Vizitiu, D. Functional cyclodextrins. 1. Chloroacetylated cyclodextrins. Angew. Makromol. Chem. 1998, 256, 75-79.

33. Guo, Z.; Chen, X.; Zhang, X.; Xin, J.; Li, J.; Xiao, H. Effective syntheses of per-2,3-di- and per-3-O-chloroacetyl- $\beta$-cyclodextrins: A new kind of ATRP initiators for star polymers. Tetrahedron Lett. 2010, 51, 2351-2353.

34. Birnbaum, W.; Kuckling, D. Synthesis of $\alpha$-biotinyl poly(ethylene glycol- $b$ - $N$-isopropylacrylamide) block copolymers with different fluorescent dyes at the $\omega$-side. Polym. Chem. 2012, 3, 2039-2049.

35. Pintauer, T.; Matyjaszewski, K. Structural aspects of copper catalyzed atom transfer radical polymerization. Coord. Chem. Rev. 2005, 249, 1155-1184. 
36. Teodorescu, M.; Matyjaszewski, K. Atom transfer radical polymerization of (meth)acrylamides. Macromolecules 1999, 32, 4826-4831.

37. Rademacher, J.T.; Baum, M.; Pallack, M.E.; Brittain, W.J. Atom transfer radical polymerization of $\mathrm{N}, \mathrm{N}$-dimethylacrylamide. Macromolecules 2000, 33, 284-288.

38. Teodorescu, M.; Matyjaszewski, K. Controlled polymerization of (meth)acrylamides by atom transfer radical polymerization. Macromolecules 2000, 21, 190-194.

39. Neugebauer, D.; Matyjaszewski, K. Copolymerization of $N, N$-dimethylacrylamide with $N$-butyl acrylate via atom transfer radical polymerization. Macromolecules 2003, 36, 2598-2603.

40. Xia, A.; Burke, N.A.D.; Stöver, H.D.H. End group effect on the thermal response of narrow-disperse poly( $\mathrm{N}$-isopropylacrylamide) prepared by atom transfer radical polymerization. Macromolecules 2006, 39, 2275-2283.

41. Heskins, M.; Guillet, J.E. Solution properties of poly( $N$-isopropylacrylamide). J. Macromol. Sci. Chem. A 1968, 8, 1441-1455.

42. Schild, H.G. Poly(N-isopropylacrylamide): Experiment, theory and application. Prog. Polym. Sci. 1992, 17, 163-249.

43. Plummer, R.; Hill, D.T.J.; Whittaker, A.K. Solution properties of star and linear poly( $N$-isopropylacrylamide). Macromolecules 2006, 39, 8379-8388.

44. Pamies, R.; Zhu, K.; Kjoniksen, A.-L.; Nyström, B. Thermal response of low molecular weight poly-( $N$-isopropylacrylamide) polymers in aqueous solution. Polym. Bull. 2009, 62, 487-502.

(C) 2015 by the authors; licensee MDPI, Basel, Switzerland. This article is an open access article distributed under the terms and conditions of the Creative Commons Attribution license (http://creativecommons.org/licenses/by/4.0/). 